\title{
Cambio y continuidad en relaciones internacionales: la conexión inglesa
}

$\mathrm{R}$ elaciones internacionales (la disciplina) no es un arte. Al esculpir, por ejemplo, cuando el artista talla el material para darle forma, el diseño es en buena medida dictado por el material utilizado. Mientras que la madera no determina lo que el artista hará con ella, sí posee ciertas propiedades físicas que son independientes de la voluntad del artista, y por lo tanto impone límites al grado al cual puede ser "interpretada". Los escultores, por tanto, utilizan herramientas y técnicas apropiadas para el material con que trabajan. Los teóricos de relaciones internacionales, en contraste, están normalmente más limitados por las que son consideradas prácticas científicas apropiadas; pero, puesto que no trabajan con elementos físicos, se podría argumentar que tienen más espacio que los artistas para enfrentar su "material". El orden internacional o el balance de poder, por ejemplo, no poseen características independientes de nuestros estados mentales; así, la decisión del investigador respecto de cómo manejar su "material" depende de la manera en que lo percibe. Sin embargo, como sugerí arriba al referirme a "prácticas científicas apropiadas", esto no significa que todo vale en la disciplina. Como una empresa colectiva, las ciencias sociales en general, y las

* Profesor investigador del Departamento de Estudios del Pacífico de la Universidad de Guadalajara, e investigador del sNI. relaciones internacionales en particular, tienen ciertas normas respecto de lo que se considera práctica válida.

Sugiero que es precisamente la concepción que el investigador tiene de su objeto de estudio (es decir, de su "material") lo que en buena medida establece el carácter de la empresa. Esto es, la manera en que el investigador se aproxima a su "tema" involucra posiciones tanto epistemológicas como ontológicas que determinan no sólo las preguntas que planteará, sino también las respuestas que buscará. El momento ontológico tiene que ver con lo que el investigador decide que existe y cómo funciona, en tanto que el epistemológico se refiere a las reglas para decidir que un argumento es más persuasivo que otro. ${ }^{1}$ En este sentido podemos concebir la ontología como el material con que el investigador decide trabajar, y la epistemología como la técnica que decide utilizar - la cual, por supuesto, tiene que ser apropiada a lo que juzga es la naturaleza de su objeto de estudio.

Sin entrar en el debate respecto de si la ontología determina la epistemología, o viceversa, en este breve ensayo sugiero que el enfoque constructivista en relaciones internacionales representa una continuación de la escuela realista en lo referente a estos dos elementos pre-teóricos (es decir, no sus planteamientos sustantivos). Puesto que sostendré que la escuela inglesa representa un puente entre el realismo y el constructivismo, comienzo revisando so- 
meramente la posición de dicho enfoque en estos aspectos. Paso entonces a considerar los componentes normativos presentes en la escuela realista, y posteriormente los elementos realistas en la perspectiva constructivista. En la cuarta sección hago más explícito el enfoque pre-teórico compartido por las tres perspectivas. En la sección final ilustro dicha continuidad con el realismo cultural de Alastair Johnston.

\section{La conexión inglesa}

Hedley Bull, el más conspicuo exponente de la llamada escuela inglesa, consideraba la política mundial como una materia eminentemente social. Estaba interesado en la sociedad internacional, la cual, para él, "existe cuando un grupo de Estados, consciente de ciertos intereses y valores comunes, forma una sociedad en el sentido de que conciben que ellos están unidos por un conjunto de reglas comunes en sus relaciones recíprocas". ${ }^{2}$ La sociedad internacional cristalizó en los siglos XVIII y XIX con el surgimiento de cinco instituciones internacionales que refleja-

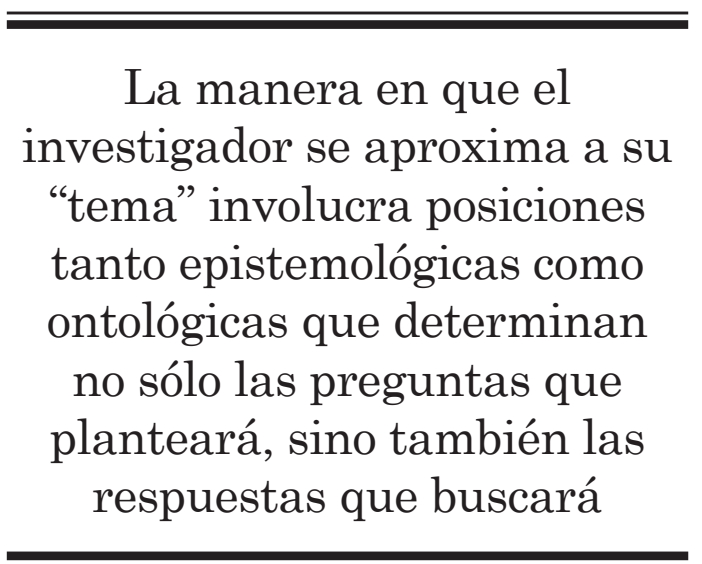

ban la cooperación de sus miembros: el derecho internacional, el sistema diplomático, el balance de poder como un objetivo explícito, y la noción de potencia (great power); la guerra, entendida como "un patrón definido de comportamiento, orientado a la promoción de objetivos comunes", es la quinta institución de la sociedad internacional. ${ }^{3}$

Fueron estas instituciones las centrales en el análisis de la política mundial que Bull llevó a cabo. Para él, "El funcionamiento de la sociedad internacional debe ser entendido en términos de sus instituciones propias, distintivas." ${ }^{4}$ Bull concebía las instituciones como la materialización de reglas y valores comunes. Sostenía que era precisamente la posesión de un marco cultural común lo que posibilitó el surgimiento de la sociedad (europea) internacional. Pero Bull no era un idealista: él reconocía que la sociedad internacional moderna surgió "de la cultura de las potencias occidentales dominantes", ${ }^{5}$ y que en este sentido fue impuesta a los Estados no europeos. El poder no está ausente en su interpretación.

Aún más, como los autores de la tradición realista, Bull concebía la anarquía como "el dato central de la vida internacional y el punto de partida para el análisis". Como ellos, Bull era estatista: la suya era una sociedad internacional de Estados. ${ }^{6}$ No estaba interesado en conceptos tales como "opinión pública mundial”, como sí estuvieron los llamados idealistas del periodo entre guerras. Por eso podía afirmar que "la parte sustantiva del análisis de [Edward] Carr respecto de lo que es la política internacional es correcta". ${ }^{7}$ Bull ubicaba su trabajo claramente dentro de la tradición clásica, la cual, según él, "deriva de la filosofía, la historia y el derecho". ${ }^{8}$ Como ha señalado Kalevi Holsti, existía un consenso entre los autores de esta tradición (en la cual incluye la obra de Bull y Hans Morgenthau) acerca del "objeto de estudio de la teoría internacional". ${ }^{9}$ En este sentido Bull puede considerarse como realista. 
Pero, aunque Bull otorgaba primacía ontológica a los Estados, consideraba que ellos estaban insertos en instituciones internacionales. Afirmaba que: "El elemento de la sociedad internacional es real, pero los elementos del estado de guerra y de lealtades transnacionales y divisiones es real también, y cosificar el primer elemento, o hablar como si anulara el segundo y el tercero, es una ilusión". ${ }^{10}$ Es aquí donde Stanley Hoffmann ha encontrado la "tensión entre su realismo y su énfasis en las reglas e instituciones, las cuales mitigan la anarquía". ${ }^{11} \mathrm{Y}$ es aquí también donde reside la importancia de Bull para el enfoque constructivista. Las normas son una constante en su obra. Bull mantenía que: "El elemento de la sociedad internacional siempre ha estado presente en el moderno sistema internacional porque no se puede decir que en etapa alguna la concepción de los intereses comunes de los Estados, de las reglas comunes y de las instituciones por ellos elaboradas, han dejado de existir". ${ }^{12}$ Para él, la pregunta fundamental "es si un sistema internacional en el cual es necesario tener un pretexto para iniciar una guerra no es radicalmente diferente de otro en el que esto no es así". ${ }^{13}$

Todavía más, anticipando la preocupación constructivista respecto de la cuestión "agente-estructura", Bull observó que "la idea de la sociedad internacional tiene importantes raíces en la práctica internacional real", y que "los Estados cambian las reglas al demostrar, a través de sus palabras o acciones, que están retirando su consentimiento a reglas viejas y otorgándoselo a otras nuevas, y así alterando el contenido de la costumbre o práctica establecida". ${ }^{14}$ Sin embargo, de una manera que recuerda la concepción de Alexander Wendt sobre las estructuras normativas, Bull argumentaba que "las reglas no son infinitamente maleables y de hecho constriñen el rango de elección de los Estados que buscan articular pretextos en términos de ellas". ${ }^{15}$ Aún más, Bull distinguía entre reglas constitutivas y regulativas —una distinción básica de la literatura constructivista. ${ }^{16}$

Gerrit W. Gong, uno de los discípulos de Bull, introdujo lo que luego sería una de los temas centrales del enfoque constructivista: la identidad. Gong notaba que: "El estándar de civilización (...) contribuyó a definir la identidad interna y las fronteras externas de la sociedad internacional dominante del siglo XIX". ${ }^{17}$ Bull parecía estar al tanto de la importancia de las prácticas discursivas en la política mundial; escribió, por ejemplo, que los plebiscitos y el principio de autodeterminación vinieron a "determinar el tipo de justificaciones que se podía ofrecer por lo que se hiciera". ${ }^{18}$ Como la mayoría de los constructivistas, Bull estaba interesado en los efectos causales de las normas: "El hecho de que todas las creencias morales estén social o históricamente condicionadas no significa que carezcan de fuerza causal independiente, como tampoco debe deducirse de ello que los desacuerdos morales puedan resolverse por medio de la discusión racional”. ${ }^{19}$

\section{La interpretación realista}

Los Estados están ontológicamente dados para los realistas. ${ }^{20}$ Morgenthau sugirió el concepto del "interés nacional definido en términos de poder" como la "señal principal que ayuda al realismo político a encontrar su camino a través del paisaje de la política internacional". ${ }^{21}$ Pero su entendimiento del poder y del interés nacional era tanto social como interpretativo. El elemento interpretativo es claro, por ejemplo, cuando señala que el interés nacional está conti- 
nuamente sujeto a los errores de la mala interpretación por parte de los estadistas, ${ }^{22}$ y cuando escribe que el realista trabaja como si estuviera viendo por arriba de los hombros del estadista. ${ }^{23} \mathrm{El}$ elemento social es evidente, por ejemplo, en su pronunciamiento de que "el realismo político contiene no sólo un elemento teórico, sino también uno normativo, ${ }^{24}$ y en su concepción del poder. Por este último Morgenthau se refería al "control del hombre sobre las mentes y las acciones de otros hombres", y por poder político a "las relaciones mutuas de control entre los detentadores de la autoridad pública y la gente en general". ${ }^{25}$ Aún más, Morgenthau sostenía que la lucha por el poder entre los Estados no es necesariamente un juego de suma cero, puesto que sus respectivos intereses nacionales pueden y deben ser definidos en términos de los intereses de otros Estados. ${ }^{26}$ Por eso él se refería también al sistema actual de Estados como "una sociedad internacional de naciones soberanas". ${ }^{27}$

\section{Construyendo el realismo}

El constructivismo otorga primacía ontológica a la estructura, y al considerarla como intersubjetiva se ubica cerca de la escuela inglesa. Como el realismo, sin embargo, el constructivismo considera los Estados como la principal unidad de análisis. ${ }^{28}$ Más específicamente, como John Gerard Ruggie observa:

[...] los constructivistas sostienen que los pilares básicos de la realidad internacional son tanto ideacionales como materiales; que los factores ideacionales tienen dimensiones normativas e instrumentales; que expresan no sólo una intencionalidad individual sino también una colectiva, y que el sentido y el significado de los factores ideacionales no son independientes del tiempo y del espacio. ${ }^{29}$
También como el realismo, el cual, advierte Robert Gilpin, "debe ser visto como una orientación filosófica y un conjunto de supuestos más que como una teoría 'científica' en un sentido estricto", ${ }^{30}$ "el constructivismo sigue siendo más una perspectiva filosófica y teóricamente conformada sobre las relaciones internacionales". ${ }^{31}$

El énfasis constructivista en las normas no tiene nada que ver con proyectos utópicos; como muchos de sus proponentes han reiterado, las normas internacionales llevan consigo relaciones de poder. Así, Wendt ha señalado que "el realismo no detenta el monopolio sobre el aspecto feo y brutal de la vida internacional". ${ }^{32}$ Lo que está en la palestra ahora es cómo estudiar la vena de la política internacional, una vena que no cabe fácilmente en el ámbito de las epistemologías racionalistas. Como sus predecesores en la tradición clásica, los constructivistas abrevan de los historiadores, filósofos y sociólogos. Esto no es una mera coincidencia: es más bien evidencia de que ambos enfoques comparten una concepción similar de su campo de estudio.

\section{El continuo pre-teórico}

A pesar de que los realistas, miembros de la escuela inglesa y constructivistas moderados $^{33}$ creen en la importancia de los argumentos racionales, ellos no son entusiastas de la versión neopositivista del método científico en la disciplina. Así, Morgenthau observó que "el racionalismo malinterpreta el carácter del hombre, el carácter del mundo y el carácter de la razón misma”. ${ }^{34}$ Adelantándose al tono interpretativo tanto de la escuela inglesa como del constructivismo, Morgenthau se lamentaba de que: "La concepción cientificista de la naturaleza y de la sociedad [...] ha descubierto las causas de muchas cosas 
aisladas. Pero no ha buscado una conexión significativa de todas esas cosas aisladas, ni de su naturaleza, no digamos ya de su propósito y valor para el hombre." ${ }^{35}$

De manera similar, Bull insistía en que:

Si existe algún utopianismo en la materia que necesita ser traído bajo control, es un utopianismo que se refiere no a la política internacional sino a los límites del conocimiento acerca de ella, de las posibilidades de un tratamiento estrictamente científico de todas sus dimensiones. ${ }^{36}$

Él pensaba que:

[...] al confinarse ellos mismos a lo que puede ser comprobado lógica o matemáticamente, o verificado de acuerdo con procedimientos estrictos, los practicantes del enfoque científico se están negando a ellos mismos los únicos instrumentos que en la actualidad están disponibles para lidiar con lo sustantivo de la disciplina. ${ }^{37}$

También en la misma vena, Ruggie ha observado que el constructivismo puede ser visto "como una reflexión crítica de los límites del neo-utilitarianismo", tal como se ha materializado en las teorías racionalistas y que, en consecuencia, "el constructivismo es a- o post- positivista en su epistemología". ${ }^{38}$

\section{Realismo cultural}

Una ilustración relevante de las similitudes entre los enfoques constructivista y realista es el "realismo cultural" de Alastair Johnston. ${ }^{39}$ En su trabajo sobre la cultura estratégica china, Johnston argumenta que la persistencia del comportamiento realpolitik chino no está relacionada ni con la estructura anárquica del sistema internacional ni con la distribución de capacidades. ${ }^{40}$ Para él, es la cultura estratégica, ${ }^{41}$ en su interacción con factores estructurales como variables intervinientes, lo que da lugar a la variación de la elección estratégica. ${ }^{42}$ Debido a que el factor cultural es mantenido constante, la variación en la estrategia está dada por los cambios en el ambiente material. Sin embargo, "las implicaciones de estos cambios [...] dependen del contenido ideacional de la constante". ${ }^{43}$ Esto es, debido a que el contenido de la premisa del realismo estructural sobre el comportamiento estatal "habita las percepciones del tomador de decisiones $y$ persiste a través de diferentes contextos estructurales", es independiente de la estructura. ${ }^{44}$ Johnston concluye que, a pesar de que los neorrealistas no lo reconocen, su supuesto acerca de las preferencias estatales deriva de culturas estratégicas de tipo realpolitik..$^{45}$

Johnston ofrece dos contribuciones metodológicas importantes: 1. Demuestra cómo una constante, cuando es entendida propiamente como imbuida de significado, no necesariamente necesita salir del análisis, como la ontología asocial de Kenneth Waltz lo sugiere, ${ }^{46}$ y 2 . No divorcia los factores materiales de los ideacionales, como hacen los neorrealistas. Johnston hace un excelente trabajo al ilustrar empíricamente y complementar el planteamiento de Wendt de que la anarquía es socialmente construida. ${ }^{47}$ Sin embargo, considero que no explota el potencial de su propio argumento teórico. La tesis de Johnston acerca de la cultura estratégica como el origen del comportamiento de auto-ayuda en el sistema internacional es correcta, pero dice poco acerca de sus orígenes. ¿Por qué no indagar el contenido ideacional de diferentes estructuras anárquicas? Johnston critica a los neorrealistas por estirar el concepto de anarquía, esto es, por no reconocer los diferentes tipos de anarquía que han existido históricamente. ${ }^{48}$

Johnston reconoce que "no todos los sistemas anárquicos producen el mismo grado 
de incertidumbre y miedo", ${ }^{49}$ pero relaciona esas diferencias sólo con la distribución de capacidades materiales. Siguiendo a la escuela inglesa, y particularmente la distinción establecida por Martin Wight respecto del "sistema internacional de Estados" y el "sistema de Estados suzeranos", sostengo que esta constante de tercera imagen también está imbuida de significado. Así, una lectura de la anarquía que sea sensible a la historia, así como a la distribución de capacidades materiales, podría ayudarnos a explicar el surgimiento de culturas estratégicas de segunda imagen - como es el caso, precisamente, de la china-. Por esto la escuela inglesa, con su aguda percepción histórica y su enfoque más orientado a la sociología, puede servir como un sólido puente entre el realismo y el constructivismo.

Los realistas, los teóricos de la sociedad internacional, y los constructivistas saben que los brutos y lánguidos instrumentos del utilitarianismo no son los más apropiados para tallar el "esencialmente inmanejable material” que es la política internacional. ${ }^{50}$ Posiblemente haya algo estético en esta idea. Después de todo, es en el ámbito epistemológico de lo simbólico donde estos autores operan y donde, como Donald Puchala ha señalado, "los artistas moran filosóficamente". ${ }^{51}$ Quizás relaciones internacionales está más cerca de ser un arte de lo que comúnmente pensamos. ngु

\section{Notas}

1 Martin Hollis y Steve Smith, "A response: Why Epistemology Matters in International Theory", en Review of International Studies 2 (1996), pp. 111-116. Véase también David Dessler, "What's at Stake in the Agent-Structure Debate?", en International Organization 43: 3 (1989), pp. 441-473.
2 The Anarchical Society (New York, Columbia University Press, 1977), p. 13. Todas las traducciones son mías.

3 Ibíd., las primeras cuatro instituciones aparecen en la p. 37, y la quinta en la p. 74 .

4 "Society and Anarchy in International Relations", en Herbert Butterfield and Martin Wight, Diplomatic Investigations: Essays in the Theory of International Politics (Cambridge, Harvard University Press, 1966), p. 48.

5 The Anarchical Society, cit., p. 39.

6 "Society...", cit., p. 35.

7 "The Twenty Years' Crisis Thirty Years On", International Journal 24: 4 (1969), p. 627

8 "International Theory: The Case for a Classical Approach”, World Politics 28 (1966), p. 361.

9 The Dividing Discipline: Hegemony and Diversity in International Theory (Boston, Allen and Unwin, 1985), p. 7.

10 The Anarchical Society, op. cit., p. 51.

11 "Hedley Bull and His Contribution to International Relations", International Affairs 62:2 (1986), p. 186.

12 The Anarchical Society, op. cit., p. 42.

13 Ibíd., p. 45.

14 Ibíd., pp. 24 y 73.

15 Ibíd., p. 45.

16 Ibíd., pp.76-77.

17 The Standard of 'Civilization' in International Society (Oxford, Clarendon Press, 1984).

18 The Anarchical Society, op. cit., p. 35.

19 "The Twenty Years...", op. cit., p. 630.

20 Stephen D. Krasner, "Sovereignty: An Institutional Perspective", en Comparative Political Studies 21:1 (1988), p. 70.

21 Politics Among Nations: The Struggle for Power and Peace (Nueva York, Knopf, 1967), p. 5.

22 “Otro 'Gran Debate': El Interés Nacional de los Estados Unidos”, en Hans J. Morgenthau, Escritos sobre política internacional, ensayo introductorio, traducción y notas de Esther Barbé (Madrid, Editorial Tecnos, 1990), p. 109.

23 Politics Among Nations, op. cit., p. 5.

24 Ibíd., p. 10.

25 Ibíd., p. 26,

26 "Otro...", op. cit., p. 108.

27 Politics Among Nations, op. cit., p.22.

28 Alexander Wendt, "Collective Identity Formation and the International State", American Political Science Review 88: 2 (1994), p. 385.

29 "What Makes the World Hang Together? Neoutilitarianism and the Social Constructivist Challenge", International Organization 52: 4 (1998), p. 879. 
30 "The Richness of the Tradition of Political Realism", en International Organization 38: 2 (1984), pp. 289-290.

31 Ibíd., p. 856.

32 "Constructing International Politics", International Security 20: 1 (1995), p. 76.

33 Excluyo aquí a los constructivistas post-estructuralistas como Richard Ashley, David Campbell, James Der Derian, James George, y R. B.. J. Walter, porque no comparten lo que digo en los siguientes comentarios.

34 "The Tragedy of Scientific Man", en su Scientific Man vs. Power Politics (Chicago, The University of Chicago Press, 1946), p. 204.

35 "The Chimera of the Natural Sciences", ibíd., p. 124.

36 "The Twenty Years...", Op. cit., p. 632.

37 "International Theory:...", p. 366. Sin embargo, Bull señaló que "Si... el enfoque científico debe ser mantenido firmemente en un segundo plano, esto sólo se puede lograr por medio de la crítica racional (ibíd., p. 364)." De manera similar, Morgenthau observó que "la política debe ser entendida a través de la razón, y sin embargo no es en la razón donde encuentra su modelo" ("The Dilemma of Scientific Man", en Scientific Man, op. cit., p. 10). Así, no es que los realistas se opusieran a la discusión racional, sino simplemente que su concepción de ésta no era la misma que la de los enfoques racionales convencionales.

38 Op. cit., pp. 856 y 880.

39 Cultural Realism: Strategic Culture and Grand Strategy in Chinese History (Princeton, Princeton University Press, 1995), y "Cultural Realism and Strategy in Maoist China”, en Peter J. Katzenstein, The Culture of National security: Norms and Identity in World Politics (Nueva York, Columbia University Press, 1996), pp. 216-268.

40 “Cultural Realism...”, pp. 261-262. Es interesante notar que a pesar de que en algunos momentos Johnston parece estar discutiendo tanto con los realistas clásicos como con los neorrealistas (217; 228), en realidad sólo lo hace con los últimos. Evidencia de esto es que prácticamente no se ocupa del trabajo de los realistas clásicos. Por cierto, esta falta de interés en el realismo clásico es notable, puesto que Johnston llama a su propio enfoque realismo cultural.

41 Él define la cultura como "un sistema integrado de símbolos (es decir, axiomas causales, lenguajes, analogías, metáforas, etcétera) que actúa de manera que establece preferencias estratégicas generalizadas y duraderas mediante la formulación de conceptos del papel y la eficacia de la fuerza militar en los asuntos políticos interestatales, y mediante el arropamiento de estos conceptos con tal aura fáctica que las preferencias estratégicas parecen singularmente realistas y eficaces (1996: 222)."

42 Ibíd., p. 227.

43 Ibíd., p. 227, nota 24.

44 Ibíd., p. 264.

45 Ibíd., p. 264. Michael Desch, por lo tanto, yerra al escribir que el argumento de Johnston "es difícil de separar de la alternativa realista (161)". "Culture Clash: Assessing the Importance of Ideas in Security Studies”, en International Security 23: 1 (1988), pp. 141-170. Quizás es difícil para él separar el planteamiento de Johnston porque Desch piensa que el comportamiento realpolitik es sinónimo de la más simplista definición de la anarquía y de una concepción materialista de la estructura.

46 Véase Kenneth Waltz, Theory of International Politics (Nueva York, McGraw-Hill).

47 "Anarchy is What States Make of It: The Social Construction of Power Politics", en International Organization 46: 2 (1992), pp. 391-426.

48 “Cultural...", op. cit., p. 265.

49 Ibíd., p. 266, nota 14.

50 "International...", op. cit., p. 370.

51 "Woe to the Orphans of the Scientific Revolution", en Robert L. Rothstein (ed.), The Evolution of Theory in International Relations (Columbia, University of South Carolina Press, 1991), p. 51. 